\title{
African Ethics and the Moral Possibilities of Ubuntu towards Conflict Resolution in the Democratic Republic of Congo (DRC)
}

\author{
Mbangu Anicet Muyingi \\ Postdoc fellowship, Vaal University of Technology \\ Faculty of Human Sciences, Vanderbijpark, 1900 \\ Email: mbangum@vut.ac.za, anicetmbangu@gmail.com
}

\section{Doi:10.5901/mjss.2013.v4n3p561}

\begin{abstract}
The aim of this article is to discuss the influence that African ethics can exert to solve conflict peacefully in the Democratic Republic of Congo (DRC), in the light of Ubuntu as a traditional world vision. In considering Ubuntu towards conflict resolution and peace building, the article contends that African ethics, which was appropriate in traditional Africa to wage peace and maintain social harmony, can still help to establish or build conditions for deliberations in conflict resolutions by bringing about peace, justice, unity, and freedom, generally in Africa and particularly in the DRC. The idea of trying to pose the African ethics as a panacea to the conflict in the DRC has to do with, inter alia trying to open other perspectives within the scope of the search for solutions to the problems of the DRC.The findings of the external desk research methodology, which comprised online desk research (Internet) data from non-governmental organisations (NGOs), the United Nations, the African Union, and published government data, reveal the detrimental effects of conflict within the DRC. Therefore, it is evident that anybody who is seriously concerned with the welfare of the DRC needs to address the issue of ethical crisis in the resolution of conflict. The researcher draws the conclusion that an African ethics framework can be applied through an indigenous approach to conflict resolution in the DRC. This framework draws on the philosophy of Ubuntu because of its set of common characteristics or behaviours, representative of a wider value system or paradigm.
\end{abstract}

Keywords: Democratic Republic of Congo; African Ethics; Moral possibilities; Ubuntu; Conflict Resolution

\section{Introduction}

The Democratic Republic of Congo (DRC) has been, and continues to be, the scene of multiple conflicts at local, national and regional levels for at least a decade. These conflicts have led to the breakdown of the DRC as a country (Benjamin, et al. 2007). Human lives are lost, infrastructure is destroyed, education and health services have suffered, and the environment is damaged. The tie that linked Congolese together before is broken, social solidarity and cohesion has collapsed, and political tension is generated (Benjamin, et al. 2007). In addition, socio-economic development is severely retarded as a result of the consequence of conflict. In conflicts such as these, the influence of the traditional African ethics in conflict resolution plays an important role to solve conflict in the DRC peacefully, and to establish conditions of the Congolese life, freedom, dignity, right and development.

Moreover, the role of traditional African ethics, before the colonialism period, was to consider moral conduct in terms of attitude toward life, and encompasses issues of human dignity and respect, within the understanding that an individual's humanity interconnects with the dignity and humanity of others (Mabovula, 2011:4-6). Good is whatever protects and promotes human life, evil is that which destroys or alters human life (Swindler, 1992:45). Life is the supreme value in traditional African societies, and expresses itself in respect for humanity (Abiodum, 2000: 25). According to the arguments above, conflicts in the DRC should be resolved in a way that protects and promotes human life, and encompasses issues of human dignity.

The basis of this concern for human life is the African belief in the dignity of every human being. One word expresses this notion of dignity: Ubuntu (humanity). The concept of Ubuntu is the key to an understanding of traditional African ethics. It means weight, solidity, and consistency, as in the Hebrew notion of the Kabod of Yahweh ${ }^{1}$. In African ethics, a person fulfils his/her humanity (humanness) when he/she is capable of respect of own and others' humanity.

\footnotetext{
${ }^{1}$ Kabod means glory. This word derived from the word deb or Kabed, which means heavy or weighty. It is also used for liver or heart, pointing to the internal source of life. Kabod can be paraphrase as "awe inspiring Glory, which incorporates, power, majesty, might and wealth. It's (Kabod) often associated with the word Yahweh (God) (Gerald, 1968: 555).
} 
Whenever a person does not respect the life and dignity of other persons, he/she automatically loses his/her humanity because humanity is thought to be the essence of being human. It is the notion of humanity that constitutes the foundation of all traditional African ethics. Any conduct that does not respect the dignity of human life is bad; whatever contributes to the protection and the intensification of human life is good. Conflict in the DRC is bad because it is a conduct of disgrace. It divides the Congolese population by undermining interpersonal and social trust, above all destroying the social norms, values and institutions that have regulated and coordinated cooperation, and collective action, for the well-being of the Congolese community. This makes it very difficult for both the Congolese social group, and the DRC as a state, to recover their cohesion. Conflict disgraces human dignity and humanity. It does not intensify human life, instead conflict is there to diminish life and destroy infrastructure.

It is, therefore, against this background that the study sought to examine the influence that African ethics can exert to solve conflict peacefully in the DRC, to rebuild social trust, dignity, justice, unity, freedom, and development through reconciliation, in the light of Ubuntu as a world vision.

\section{Statement of the problem}

Although the international community remains committed to supporting the Democratic Republic of Congo (DRC) through the resolution of its conflict, seemingly very little has changed up to date. The country is still in conflict, which is devastating for the Congolese, as it threatens their existence, safety, security and moral dignity. Despite the elections held in 2006 and 2011, the DRC is still struggling to promote peace, justice, unity, freedom and a sustainable development. Given this situation, it becomes vital to analyse the effectiveness of African ethics' (Ubuntu) reflection on values, for instance consideration of the importance of human life, freedom, dignity and rights. The question is then: How could African ethics contribute in the resolution of conflict in the DRC?

\section{Objectives of the study}

The main objective of this paper is to evaluate the effectiveness of the traditional African ethics (Ubuntu) strategy to influence and support conflict resolution in the DRC. The specific objective is to analyse the effectiveness of conflict resolution in the DRC through the influence of traditional African ethics (Ubuntu) to promote peace, freedom, human dignity and development of the Congolese.

\section{Significance of the study}

This article is significant and relevant as a means of developing a warning system in conflict resolution, which could assist African countries, and particularly the DRC, to incorporate African traditional ethics (Ubuntu) in the resolution of their conflict for the promotion of peace, freedom, unity, human dignity and development. Conflict resolution per se is very important on the African continent, and particularly in the DRC, to ensure or to promote a better life. In recognising that the DRC is a country in which effective conflict resolution mechanisms have been and continue to be sought, it is clear that undertaking an analysis of their effectiveness, in the light of African ethics in conflict resolution, is vital. African traditional ethics (Ubuntu) could be an integral part of the process of achieving positive peace and promoting social solidarity amongst Africans, and the Congolese themselves. The findings will assist policy makers and development agencies to ascertain the appropriate conflict resolution strategies for the promotion of peace and development in the DRC. In addition, the study will be beneficial to the African countries in the sense that the results will indicate areas that need to be restructured, thereby improving the promotion of peace, human dignity, justice, unity and development, on the continent in general, and in the DRC in particular.

\section{Delimitation of the Study}

The purpose of demarcating a study is to make it more manageable and focused. Due to the logistical constraints of covering the entire African continent, the study will focus only on the DRC. The study focuses on the DRC because the country has experienced conflict since independence; and this is, of course, a challenge to human existence and moral dignity. The DRC is a country in which effective conflict resolution mechanisms have been and continue to be sought, yet social conflict remains that disgraces human existence and the moral dignity of the Congolese (Mpangala, 2004:17). The 
study covers the entire country, which makes it easier to generalise the effectiveness of African ethics support to conflict resolution.

\section{Literature review}

\subsection{Concept of conflict}

Conflict is a fluid and ambiguous concept. In Latin, conflict means 'clash or engage in fight' (Kaarsholm, 2006). According to Duffield (2001:21), conflict is a multi-dimensional social process, which is a common and essential feature of human existence. When expressed and handled constructively, conflict can act as a catalyst for personal, socio-political and economic development and transformation. When expressed destructively, conflict fosters violence and affects human life, dignity, and development goals, which is the case in the DRC. Rummel (2003:1-2) argues that conflict is necessary to our understanding and appreciation of reality and human action. Conflict can be treated broadly as a philosophical category denoting the clash of power against power in the striving of all things to manifest and fulfill themselves (Rauche, 1994: 18). Conflict is a confrontation between one or more parties aspiring towards incompatible or competitive means or ends. Miall et al. (2005:80) define conflict as the pursuit of incompatible goals by different groups or individuals. The use of this definition allows for the consideration of any conflict, whether it is interpersonal or international, pursued by peaceful means or by the use of force, or pursued by the government or civil society. According to Eze (2008:34-37), conflict may be either manifest inter alia recognisably through action and behaviours, or latently, in which case it remains dormant for some time as incompatibilities are unarticulated or are built into systems or such institutional arrangement as governments, corporations, or even civil society.

Forster (2007:210-213) identifies three general forms of conflict, these are interstate, internal, and state formation conflicts. Interstate conflicts are disputes between nation states or violations of the state system of alliances while internal and states conflicts are conflict that is taking place within the state and that are posing a severe challenge to traditional conflict management techniques (it is a an intra-state violent strife). The international community has become increasingly concerned with the rise in frequency and intensity of internal conflicts, which are contributing to the expanding nature, sophistication, and at times legitimisation, of interventionist policies. Examples of internal and state formation conflicts include civil and ethnic conflict, which is detrimental to human life and dignity in Africa, anti-colonial struggles, secessionist and autonomous movements, territorial conflicts, and battles over control of government. Today, the focus of attention is on global conflicts, where non-state groups combat internal and regional organisations (Forster, 2007:215). Conflict can also be seen as a distinct category of social behaviour of two parties trying to get something they both want but cannot both have (Miall et al., 2005:10). Moreover, conflict can be apprehended as a potentiality or a situation, as a structure or manifestation, as either an event or a process. Hence, conflict is a social phenomenon where reality comprises multiform and interwoven potentialities, dispositions, and powers. This conflict refers to the prevailing pattern of political and violent conflict and armed conflict refers to those that involve the use of force that is detrimental to human existence (Forster, 2007:116).

Finally, conflict can be defined as the expression of disagreement over something important to both or all sides of a dispute (Bassey, 2003: 65). In this case, the important thing to grasp is that it is entirely dependent on the people involved. It depends on their having a particular point of view, which may or may not have independent facts and evidence to support it, and on how they behave when they encounter an opposing point of view.

Thus, the desire to eradicate conflict and the hope for harmony and universal cooperation is the wish for a frozen, unchanging world, which has all relationships fixed in their patterns with all in balance. It is one in which we cannot hope or plan for a better tomorrow, but can only follow our inevitable course, which may be likened to the determined ups and downs of a wooden horse on a merry-go-round.

Indeed, this study employs the concept of conflict, in broad terms, to describe violence, war, and all kinds of conflicts.

\subsection{Concept of conflict resolution}

Conflict resolution is a range of processes aimed at alleviating, eliminating or transforming actual and potential violent conflict into peaceful (non-violent) processes for social development, human safety and political change (Mwajiru, 2001:5). According to Oliver (2001:22), conflict resolution is concerned with addressing the fundamental causes of conflicts and aims to produce solutions, which are mutually acceptable to all parties. Conflict resolution operates at a 
number of levels or tracks, and encompasses a range of techniques from conciliation to mediation, negotiation, and problem solving (Oliver, 2001:24).

Conflict resolution implies that the deep-rooted sources of conflict are addressed, behaviours are changed towards non-violence, attitudes are no longer hostile, and structures no longer exploitative (Klare, 2001:36). The term, conflict resolution, refers both to the process or the intention to bring about these changes, and to the completion of the process. The process of conflict resolution diagnoses its nature and applies appropriate methods in order to:

1. Diffuse the negative emotional energy involved

2. Enable the conflicting parties to understand and resolve their differences

3. Resolve the differences so as to achieve solutions that are not imposed, which have been agreed to by all the parties in conflict, and which address the root cause of the conflict to promote peace, human dignity, unity, justice, and development.

According to Abu-Nimer (1996:35-52), conflict resolution has been developed as a field since the 1950s and its emergence as an interdisciplinary field can be traced to human relations and inter-group movements, which followed the Second World War. He further argues that the creation of conflict resolution, as an academic discipline and field of practice, grew out of industrial and labour management. Out of this movement, several intervention approaches are being developed and applied to different levels of conflict. However, the main processes of conflict resolution are conciliation, facilitation, negotiation, mediation, and arbitration. Indeed, not all conflicts are harmful. Some may ultimately result in a positive impact on development or social change. According to Onigu and Albert (1999:17), although conflicts have negative connotations, many constitute an essential creative element for changing societies and achieving peace, a better life, development goals, and aspirations of individuals and groups. Moreover, conflict resolution involves recognition by the clashing parties of one another's interests, needs, perspectives, and continued existence (Miall et al., 2005:19). The most effective forms of conflict resolution identify the underlying causes of the conflict and address them through solutions that are mutually satisfactory, self-perpetuating, and sustaining. Conflict resolution can also be practiced with a variety of emphases, including but not limited to cooperation, non-confrontation, non-competition, and positive-sum orientation. Serious challenges are found when parties at times favour, for various reasons, the continuation of conflict over its resolution. In such cases, the role of external parties can be critical in creating a balance of power, enacting sanctions or incentives, or acting as neutral mediators or invested facilitators (Miller, 2005: 84). Hence, conflict resolution is a fundamental prerequisite for peace, justice, human dignity, development and stability throughout the world. The converse is also true in that unresolved conflict breeds underdevelopment and instability.

\subsection{Concept of Ubuntu as a traditional African ethic}

The traditional African worldview of Ubuntu is based on the values of humanness, caring, respect, compassion, and associated values ensuring a happy and qualitative human community life in a family spirit (Broodryk, 2004:31). Ubuntu could be described as a community-based mindset in which the welfare of the group is greater than the welfare of a single individual in the group (Kwamwangamalu, 1999:24-42). Individuality, the sense of self, is recognised as important in the concept of Ubuntu. This differs, however, from individualism, that seeks to promote selfish interests at the expense of others (Broodryk, 2002). The latter (individualism) would not be acceptable to the Ubuntu sense of morality.

Van Binsbergen (2001:19) argues that Ubuntu recognises four attributes of being human, these are human dignity, equality, universal brotherhood, and sacredness of life; these provide the most desirable state of life in community-based living.

The communal African worldview (Ubuntu) contrasts with the more individualistic and self-centred one of Western culture. Communalism at the core of Ubuntu implies that the interests of the individual are subordinate to that of the group (Broodryk, 2002:42). The community will focus on the interests of each individual member and those activities and behaviours that will ensure the good of the group. Ubuntu is a collective solidarity, meaning that individuals will align their interests, activities, and loyalties to the group's cause and well-being (Mokgoro, 1997:45). According to Tutu (2004), Ubuntu speaks about wholeness and compassion. Tutu (2004) argues further that a person with Ubuntu is someone who is welcoming, hospitable, warm, generous and willing to share.

According to the argument above, Ubuntu stands for a communitarian morality. The goal of that morality is dignity, reached through personal growth and fulfilment. The participation of the community is the essential means to personal dignity; hence, this participation is the motive and fulfilment of the process of morality. Thus, everything that promotes personal dignity and participation in the community is good; everything that prevents it is bad. In other words, the moral possibility of Ubuntu intrinsically relates to human happiness and fulfilment within a community. This means the demand 
to participate in community, yet not only for the sake of personal fulfilment, but also for the sake of the fulfilment of the community as a whole, for only in the community is personal fulfilment thought possible (Mbiti, 1990:223-256).

Vital aspects of violent conflict are problems related to health and wealth; vital aspects of Ubuntu are health and wealth. Health and wealth are states of the whole person as a communal being (Tempels, 1959:35). The Ubuntu-attitude towards others is to treat the other as a self (Shutte, 2001:31). There is no distinction between one's own good, and the good of the community, as far as possible; everything is shared by the community. This attitude is the source of patience and of tolerance of differences between people. It is also source of the classlessness (Shutte, 2001:31) of traditional African society. In traditional African society, the leaders were the shepherds of a classless people. This attitude could be called communitarianism, in the sense of fostering moral virtues, which bring people together to live in respect for each other in a way that defines self-respect. For oneself, Ubuntu takes the form of integrity, solidity or wholeness of character and spirit that is present in one's judgments, decisions and feelings. This shows itself in confidence and endurance, in joyfulness and vitality, and in a general sense of one's own value and dignity together with others. Thus, ethics is essentially a vision of mutual perfection and fulfilment. Ethics provides such an insight by guidance in the concrete circumstances of life. Like any moral ideal, Ubuntu provide rules, and guides Africans to live a good life daily. If conflict is caused by neglect of the health of the other and unwillingness to share wealth, Ubuntu can contribute significantly to the prevention of violent conflict. This is also true of conflict in the DRC.

\section{Theoretical Framework}

The indigenous theory is used to underpin this study. Based on the works of Murithi (2000:16), one of the prescriptions of the indigenous paradigm to conflict resolution is that peace processes must also include local populations in order to be effectively grounded in their realities, and so able to address their grievances. The indigenous approach is an approach that evolved local institutions and mechanisms, through processes of internal as well as external dialogues, to respond to the emerging social, political, and economic situations. That is traditional African structure such as Ubuntu, which is based on the values of humanness, caring respect, compassion, and associated values ensuring a happy and qualitative human community life in a family spirit (Broodryk, 2004:30). In response to the argument above, in conflict resolution, the international community and the DRC government should bring the influence of indigenous African ethics, such as Ubuntu, to support conflict resolution in the DRC, by including Congolese indigenous local leaders.

In the indigenous paradigm, conflict resolution has to include the expansion of new methods of solving conflict in the African context, in order to promote peace, human life, dignity, and development (Francis et al., 2004:15). The goal of including new methods is to have valuable insights that can inform the rebuilding of social trust and restoration of the conditions for communal coexistence. Thus, peace, human life, dignity and development can only be achieved through the expansion of new methods of conflict resolution such as traditional African ethics (Bob-Manuel, 2000: 32). Indeed, the indigenous approach constitutes the glue for socio-cultural and political cohesion. For that reason, this study still supports the indigenous approach in a sense that indigenous conflict resolution had a significant degree of success in maintaining order and ensuring the peaceful coexistence of groups in pre-colonial Africa (Yakubu, 1995:6-7). The existing conflict resolution in the DRC is failing because there is no a proper resolution that is linked to the traditional African ethics to stop conflict in the country peacefully.

\section{Research Methodology}

The approach in this article is of a second-order nature. Whereas studies of a first-order nature engage in empirical observation, that is the collection and investigation of immediate experiential data, this approach consists of an analysis of the concept of African ethics in the light of Ubuntu. Traditionally one of the five main branches of philosophy, ethics, enquires into human relationships in terms of the problem of good and evil, in other words, the values and norms directing human actions and interactions. As such, it moves on a second-order level of concept, method and practice and provides first-order insight into the context of such enquiries. Thereby, it is shown that conceptual frameworks are vital to explain the meaning of the actions and activities of people in various contexts. It follows that the analysis of such frameworks - in this case the underlying ethical value-sets - will inform the understanding of human relations.

The basic data about the understanding of conflict and core ethical concept is collected through a study of books, previous research and articles relevant to the topic. The researcher also relied largely on the Internet, which has become a reservoir of information in modern society. However, the challenge that arose from using the internet is crafting searches and questions that will return the most relevant information. Despite this challenge, much data was gathered 
from this source. Although the focus is on conflict in the DRC, this will only serve as a case study to demonstrate the applicability of the African ethics the researcher is analysing. Thus, this article is designed to remain on the second-order level. Again, the study will only move to a first-order level as far as the exploration of the eventual empirical consequences of the discussed concepts.

\section{Discussion and Recommendation of Ubuntu to the Conflict of the DRC}

To recapitulate the argument above, Ubuntu stands for a communitarian morality. The goal of that morality is dignity, reached through personal growth and fulfilment. The participation of the community is the essential means to personal dignity; hence, this participation is the motive and fulfilment of the process of morality. Thus, everything that promotes personal dignity and participation in the community is good and everything that prevents it is bad. In other words, the moral possibility of Ubuntu is related intrinsically to human happiness and fulfilment within a community. This means the demand to participate in community, yet not only for the sake of personal fulfilment, but also for the sake of the fulfilment of the community, for only in the community is personal fulfilment thought possible.

Could Ubuntu, in the sense of communal dignity, help end the conflict and install peace in the DRC? The study intends to prove that it could. From the moral concept of Ubuntu emerge several demands for peace and the promotion of human life and dignity. Firstly, the demand is that Congolese should choose to live together in the traditional spirit of brotherhood; a community where mutual respect and solidarity for the sake of the health and wealth of the other is highly valued. This means a return to the communitarian spirit, observing and obeying the rules of society for the harmonious adjustment of the interests of the community rather than individuals. This presupposes settled agreements within the community, and such agreements should not exclude anyone. This is the minimum ethical behaviour required from people in support of the community.

Second, the Congolese should be generous, hospitable, and honest amongst themselves in fostering the health and wealth amongst each other. Concretely, this means that they must share the resources of their community and no one should be below anyone else. They should all be equal, because equality is the most basic principle of Ubuntu morality. Congolese leaders must know that killing innocent people for their personal gain is not permissible. The search for personal gain or interest is not in accordance with Ubuntu. Practically traditional models of conflict resolution, aligned to Ubuntu, should be explored. Such models should aim at the reestablishment of relationships between the Congolese. There must be a holistic approach to the process, in which the whole (Congolese) community should be involved, to assist on the road to peace. The Congolese leaders' responsibility is to guide conflict resolution processes towards an agreement, which should reflect, as much as possible, the consensus of all the parties involved in conflict.

Furthermore, the Congolese should develop a form of communalism in which all the ethnic groups will find a collective role and space in society. It is most particularly in this respect that the concept of Ubuntu could be re-articulated in the DRC context. The Congolese ethnic groups should share in the values of Ubuntu, the values of collective solidarity, cohesion, compassion, care and collective stewardship. The Congolese, as a people, ought to define themselves in a positive and collective sense before the international community. If they focus on their similarities and not on their differences, they can achieve this sense of a shared identity and fate. After all, how different are the Baluba (Congolese ethnic group) from the Bangala (another Congolese ethnic group) or how different are the Bakongo (Congolese ethnic group) from the Bashuahili (another Congolese ethnic group)? Indeed, the Congolese should experience the exciting meaning of humanist communitarianism to avoid conflict between them. Fukuyama (1995:17) argues that societies beset by barriers of distrust based on class, ethnicity, kinship or other factors, will face extra roadblocks in their adoption of new organisational forms. Indeed, the Congolese leadership's task is to create inter-ethnic trust and to overcome the tragedy of ethnic conflict. They should create a climate among their civilians conducive to a peaceful negotiation of an end to armed conflict, a climate of social dignity - a climate of humane communitarianism. Thus, the Congolese need to develop the spirit of Ubuntu in their society by respecting and accepting the values and principles, which should be the basis for creating a collective shared communal identity. It is also the task of the Congolese leadership to craft, canonise and permit the values of Ubuntu to work in their society. This will help the Congolese to articulate a shared vision of Ubuntu, which will act as a compass in the sea of confusion created by armed conflict.

The appeal of Ubuntu ethics to the DRC people is to reconsider the value of reappropriating traditional African values, based upon the spirit of humanity manifested in sharing, caring and advancing the good of society, in order to restore the authenticity of the philosophy of communitarianism, as it is believed to have existed some centuries ago. Those Congolese individuals, organisations, parties and leaders that disrespect these traditional African values need to 
be held accountable should their views, programmes, and actions endorse the escalation of conflict, which will hopefully prevent conflict escalating into confrontation.

\section{Conclusion}

This paper has attempted to articulate the influence that African ethics can bring to address the challenges of conflict resolution in the DRC. It has highlighted the need for the traditional African ethic approaches in conflict resolution in the DRC. It has tried to define the concept of conflict and conflict resolution, and described the African ethical approaches, in the light of Ubuntu, to conflict resolution. It is shown that conflict resolution should be based on indigenous African ethical concepts such as the Ubuntu approach of communitarism rules of perpetual peace. In fact, such an approach aligns to the traditional value, namely the protection of the dignity of the person. It also ties in meaningfully with the promotion of character virtues among all peoples, and no less, people in leadership positions; and for the same reason, will be sensitive to demonstrable facts of equal sharing of useful resources.

A communitarism rule of peace, the virtuous application thereof in the best interests of all and done so in view of traditional communal wishes and needs, will most likely ensure the universal victory of dignity over inhumanity.

\section{References}

Abiodum, R. (2000). A history of art in Africa (Preface). (In Abiodum, R., Visona, M.B., Poynor, R., Cole, H.M. \& Harris, M.D., eds. A history of art in Africa. Upper Saddle River: Prentice Hall.)

Abu-Nimer, M. (2000). Conflict resolution approaches: culture and religion: toward training model for interreligious peacebuilding. Journal of Peace Research, 38(6): 685-704.

Bassey, C.O. (2003). The nature and dynamics of civil war in West Africa. (In Aniadu, S., ed. Civil wars, child soldiers and post conflict peace building in West Africa. Ibadan: College Press.)

Benjamin, C., Pascal, N., Flavien, M., Colleen, H., Valerie, N.B., Tony, S., Jennifer, L. \& Richard, B. (2007). Mortality in the DRC: an ongoing crisis. Report retrieved in March 21. 2013. p. 26.

Bob-Manuel, I. (2000). A culture approach to conflict transformation: an African traditional experience. Term paper. Written for the course: Culture of Peace and Education taught at the European Peace University Stadtschlaining. Australia.

Broodryk, J. (2002). Ubuntu. Life lessons from Africa. Pretoria: National Library.

Broodryk, J. (2004). Ubuntu: life lesson from Africa. Pretoria: Ubuntu School of Philosophy.

Duffield, M. (2001). Global Governance and the New Wars, London: Zed.

Eze, M.O. (2008). What is African communitarianism? Against consensus as a regulative ideal. South African Journal of Philosophy, 27(4): 386-399.

Francis, D. (2004). Dangers of co-deployment: UN cooperative peacekeeping in Africa. Aldershot: Ashgate.

Forster, D. (2007). Identity in relationship: the ethics of Ubuntu as an answer to the impasse of individual consciousness. (In Du Toi, C.W., ed. The impact of knowledge systems on human development in Africa. Pretoria: Research institute for Theology and Religion. University of South Africa. p. 245-289.)

Fukuyama, F. (1995). Trust: the social virtue and the creation of prosperity. New York: Free Press.

Gerald, A. L. (1968). Old Testament life and literature. New York. Criterion Books.

Kaarsholm, P. (2006). Violence, political culture, and development in Africa. Oxford: James Currey.

Klare, M.T. (2001). Resource war: the new landscape of global conflict. New York: Metropolitan.

Kwamwangamalu, N.M. (1999). Ubuntu in South Africa: a sociolinguistic perspective to a Pan-African concept. Journal of Critical Arts, 13(5): 24-42.

Mabovula, N.N. (2011). The erosion of African communal value: a reappraisal of the African Ubuntu philosophy. Inkanyiso, 3(1): 38-47.

Mbiti, J. (1990). African religions and philosophy. New Hampshire: Heinemann. p. 223-256.

Miall, H., Ramsbothan, O. \& Woodhouse, T. (2005). Contemporary conflict resolution: the prevention, management and transformation of deadly conflict. Cambridge: Polity Press.

Miller, C. (2005). A glossary of terms and concepts in peace and conflict studies. Geneva: University for Peace.

Mokgoro, Y. (1997). Ubuntu and the law in South Africa. Seminar report of the Colloquium. Johannesburg: Konrad-Adenauer Stiftung.

Mpangala, G. (2004). Origins of political conflicts and peace building in the Great Lakes region. Institute of Development Studies. University of Dar Es salaam. Paper presented at a Symposium on Ramifications of Instability in the Great Lakes Zone, Arusha: Unpublished paper (On file with author).

Murithi, T., ed. (2000). All-Africa conference on African principles of conflict resolution and reconciliation, November 8-12, 1999, United Nations conference centre-ECA. Ethiopia: Addis Ababa

Mwajiru, M. (2001). Conflict management in Africa: lessons learnt and future strategies. Nairobi: Center for Conflict Research and Frendrich Ebert Stifling.

Oliver, P.R. (2001). Rethinking conflict resolution: the linkage problematic between "track I" and "track II". Journal of Conflict Studies, 21(2): 24 
Onigu, O. \& Albert, I.O., eds. (1999). Community conflicts in Nigeria: management, resolution and transformation. Ibadan: Spectrum Books.

Rauche, G.A. (1994). A student's key to ancient Greek thought. Pretoria: Kenau Press.

Rummel, R.J. (2003). Dimensions of conflict behaviour within nations. Journal of Conflict Resolution, 10(2): 65-73.

Shutte, A. (2001). Ubuntu: an ethics for a new South Africa. Pietermaritzburg: Luster.

Swindler, L. (1992). The meaning of life at the edge of the third millennium. New York: Paulist Press.

Tamara, D. (2000). Cultural issues in contemporary peacekeeping. (In Woodhouse, T. \& Ramsbotham, O., eds. Peacekeeping and conflict resolution. London: Frank Cass Publishers.

Tempels, P. (1959). Bantu philosophy. Paris: Presence Africane.

Tutu, D. (2004). God has a dream: a vision of hope for our time. New York: Doubleday.

Van Binsbergen, W. (2001). Reconciliation: a major African social technology of shared and recognized humanity (Ubuntu). Rotterdam: Erasmus University Press.

Yakubu, D. M. (1995). Conflict resolution in traditional African societies and present day realities: the Tiv experience. Paper presented at a seminar organized by the Centre for Nigerian Cultural studies. Ahmadu Bello University: Zaria. July. 